Teaching \& Learning (2011) 6(1), 41-52

\title{
Preparing Future Teachers To Embrace Diversity: A Collaborative Co-Instructional Approach
}

\author{
CHRISTINA SKOROBOHACZ* \\ Brock University Doctoral Student \\ MAY AL-FARTOUSI \\ Brock University Doctoral Candidate
}

\begin{abstract}
In this paper the authors reflect upon their unique experiences co-instructing a large undergraduate Diversity Issues course from the perspectives of a White Canadian woman and Middle-Eastern Muslim woman collaborating together for a shared vision of social change. They argue that merging cognitive and sociocultural studies is necessary in order to prepare dominant groups to participate more effectively in pedagogical activities related to social justice. They analyze their co-instructional approach and offer a series of recommendations that may assist institutions, programs, and instructors with preparing teacher candidates to be ready to embrace the many forms of diversity that exist within Canadian classrooms.
\end{abstract}

\section{Introduction}

Learning about diversity and social justice presents great emotional and cognitive challenges for students (Goodman, 2001). Most importantly, without understanding students' attitudes and beliefs, instructors will not be able to provide a suitable environment for such change to occur, as students may be reluctant to question their worldviews due to the fear and anxiety they may experience when reflecting on "others." Educators need to become aware of their students' different behaviours, and to consider their challenges if they intend to focus on and promote social justice education. The purpose of this paper is to draw upon our experiences co-instructing a large undergraduate Diversity Issues course from the perspectives of a White Canadian woman and a Middle-Eastern Muslim woman. In the first part of the paper, we will describe briefly our diverse backgrounds, as well as our alliance, in order to elaborate on the

\footnotetext{
${ }^{*}$ Equal Authorship

${ }^{*}$ Equal Authorship
} 
importance of our collaborative co-instructional approach. Then we will provide an insightful analysis of our co-instructional approach through: (a) merging theoretical frameworks, (b) incorporating diverse learning tools, (c) identifying the barriers and tensions that we faced with this approach, and (d) suggesting some key recommendations related to teaching diversity issues to future teachers.

\section{Situating Ourselves and Our Understandings of Diversity Through Our Multiple Identities}

\section{Christina's Narrative}

As a twenty-nine year old, White, Canadian-Ukrainian, middle class, able-bodied, heterosexual, woman, and educator who is pursuing doctoral studies on a full-time basis, I realize that I speak from multiple privileged positions within the institution in terms of my race, nationality, class, sexuality, ability, and student status (van Dijk, 1993, 2002; Wall, 2008). Many of these identities afford me advantages such as access to opportunities, a voice (including representation), and ease when navigating institutional milieus (van Dijk, 1993, 2002). Yet, I am also cognizant that at times, these multiple privileged identities may contribute to my tunnel vision (or my naivety) with respect to the barriers that minorities face, and my limited consideration of the ways that particular forms of power, knowledge, and values are systematically reproduced to allow the continuation of raced, classed, gendered, and sexualized hierarchical stratifications that categorize people and perpetuate inequity and divisiveness (Brayboy, Castagno, \& Maughan, 2007; van Dijk, 1993, 2002).

\section{May's Narrative}

As a Canadian Middle Eastern, Shi’i Muslim doctoral candidate and educator, my differences are visible in terms of my accent, clothing (i.e., my headscarf), and my skin colour. My religious difference provides me with a great challenge in terms of my perseverance to fit into the Canadian secular education system. I became aware that Muslim women, as in my case, experience multiple marginalities - as they are positioned as women and as women of Colour, which in turn includes various identities (Bullock, 2002; Hamdan, 2006; Rummens, 2003; Zine, 2008). Most importantly, throughout my childhood, I learned a lot about ethnicities and different Islamic schools of thought within the same culture, such as Sunnism and Shi'ism. I 
was aware that a great amount of oppression was taking place, and my view of curricula, as being transformative, has been expanded to consider other factors such as manipulation and discourse, as well as knowledge and power (Doll \& Gough, 2002; van Dijk, 1993, 2002, 2006).

\section{Describing the Emergence of Our Alliance}

We met in our first doctoral course in the summer of 2008. Our collegial relationship quickly evolved into a close friendship. We came to recognize our shared interests and our commitments to embracing equity-conscious values, attitudes, and practices. The two of us talked about the possibility of engaging in authentic scholarly collaborations, bringing together our diverse skills and strengths, in order to work as allies in the promotion of social justiceinformed teaching and learning. To date, our collaborations have resulted in four conference presentations, two experiences co-instructing courses at the university level (one undergraduate and one master's course), the development of a Graduate Network for Aspiring Academics (a peer mentorship group for doctoral students in our program), and multiple draft manuscripts.

We came to recognize the uniqueness (and importance) of our alliance, particularly when the literature suggested a lack of solidarity, as well as an absence of mentoring and collaborating relationships between White women and women of Colour, working and studying in higher education (e.g., Mukherjee, 2001; Sethi, 2001; Turner, 2002). Our relationship was built on respect, trust, care, support, critique, and open dialogue. We valued each other's backgrounds, experiences, and lived realities, and were not afraid to ask each other difficult questions in order to understand the origins of our beliefs and biases. When the opportunity to co-instruct a Diversity Issues course arose, we saw it as a rare chance to merge our different perspectives and experiences through a collaborative approach to preparing future teachers to embrace diversity.

\section{The Classroom and University Context}

Diversity Issues in Schooling is a required course for second-year undergraduate students from various concurrent education programs at our university (physical education and integrated studies) who are working on their junior-intermediate teaching certification and their bachelor's degree (BA or BSc) at the same time. The course is broadly described as covering issues related to a diverse society and their influence in the classroom (classism, racism, multiculturalism, 
ableism, sexism, etc.) and provides strategies that lead to the goal of equity (Brock University, 2009). We co-taught this course during the winter term of the 2009-2010 academic year. It was comprised of a 2-hour lecture (once per week), and a 1-hour seminar (once per week). Nine teaching assistants were a part of our instructional team, assisting with the delivery of smallgroup seminars (approximately 20 students per seminar) and the assessment of students' work.

There were 178 students enrolled in the class. The student demographic was largely monoracial, with most of the students being White. In speaking with some of the students, we got a sense that they had limited exposure to various kinds of diversity (socioeconomic, racial, sexual, religious, etc.). This context presented some unique challenges and opportunities for engaging students in conversations around diversity issues.

\section{Our Collaborative Co-Instructional Approach: Merging Theoretical Frameworks and Incorporating Diverse Learning Tools}

Research literature concerning changing teachers’ beliefs and practices towards culturally diverse classrooms and teaching indicates that positive outcomes are predicated on the extent to which teacher candidates are enabled to apply "equity pedagogy” to raise the academic performance of students (Hollins \& Guzman, 2005). Goodman (2001) suggests that equity exists when White students are made aware of their resistance and when educators understand theoretical development frameworks (e.g., Developmental Theory, Intellectual Development, and Social Identity Development). In our work with future teachers, we integrated the use of the developmental frameworks described by Goodman (2001), as well as the sociotransformative constructivist approach and the socioconstructivist theoretical framework described by Rodriguez (1998). These frameworks are central to: (a) understanding students’ backgrounds and beliefs so they may foster self-determination, (b) attending to oppressed groups, and (c) preparing teacher candidates for-and introducing them to-equity pedagogy.

We focused on having students analyze their "individual and cultural identity profiles” (Egbo, 2009, pp. 4-5); explore their context-dependent and shifting positions of privilege and marginality through the use of guided activities and videos (e.g., McIntosh, 1990; Singleton \& Linton, 2006); explore their life histories, experiences, and the origins of their beliefs via weekly response questions; and encourage continuous critical reflection of their teaching philosophies 
during their introduction to practical case studies depicting actual dilemmas that teachers have faced when confronted with diversity issues in their classroom contexts.

Social justice education is about change and a hope of broadening attitudes, beliefs, and behaviours. During the delivery of the course, we focused on developmental theories including emotional, intellectual, and social identity development frameworks in order to understand White students' beliefs and attitudes, and to facilitate their learning and growth. However, we are aware that educators cannot force individuals to change; rather, they can provide the context, content, and process that allow learners to grow. As mentioned earlier, social justice education creates discomfort as people question beliefs about themselves, others, and the world. Therefore, educators need to create a safe environment by fostering trust between themselves and their students, which is required before learners can grapple with challenges to their belief systems. Later, we will address some of the barriers that we faced in creating a safe environment for our students.

We referred to Freire (1970) who viewed education as a path to freedom, a liberating experience in which teachers and students alike could be lead towards a mutual process of conscientization. Informed by many other researchers (e.g., Darder, Baltodano, \& Torres, 2003; Giroux 1997, 2000; McLaren 2003; Shor, 1999), we drew on their work to develop Freire’s (1970) ideas and the concept of political consciousness for both teachers and students, in order to question the curriculum. In this respect, for instance, we focused on the notion of ideological hegemony (Egbo, 2009; Gramsci, 1985) to explain how social control is practiced through curriculum knowledge to serve the ruling elites who reproduce their own economic and political power through institutional authority. We encouraged our students to learn about critical literacy programs, to critique newspaper and media representations of diversity issues, and to understand teachers' practical experiences. We brought in guest speakers who addressed a variety of issues such as: (a) supporting immigrant students through the Settlement Workers in Schools Program; (b) understanding cultural diversity from an Aboriginal perspective; (c) recognizing teachers as allies in meeting the needs of Lesbian, Gay, Bisexual, Transgender, and Questioning (LGBTQ) youth; and (d) fostering global citizenship and educational awareness through the One World Youth Project. This method transforms students' understandings of diversity through the inclusion of practical approaches and facilitates a positive conceptualization of diversity issues by pointing to successful real life experiences. 
Through our collaborative approach based upon a weekly shared dialogue in lecture that highlighted our diverse backgrounds, we attempted to illustrate different perspectives, positions, and understandings of diversity issues, thus referring to the 'discourse of possibility and critique' so that our students could see how "inequality is best understood contextually, by reference to sets of social practices and negotiations among social actors within certain structural, historical, and ideological constraints” (Giroux, 1988, p. 194).

We offered students choice in taking up issues related to diversity in Canadian schooling that were important and meaningful to them through some of our required written assignments (position paper outline, final take-home exam, etc.). Students had opportunities to incorporate feedback from their teaching assistants and consider how the learnings and insights they gained from this course informed their thinking and the development of their positions. These activities encouraged reflecting; meaning-making; connecting; locating supporting evidence; defining key terms; paraphrasing ideas, theories, and documents; as well as applying learnings to the classroom context.

\section{Identifying The Barriers and Tensions That We Faced}

Co-instructing a Diversity Issues course with 178 undergraduate students was a challenging experience. What follows, is a candid acknowledgement of multiple personal, contextual, attitudinal, and programmatic barriers that we contended with along the way. We illustrate some of these challenges by integrating students' comments from a voluntary interim feedback form that we encouraged them to complete, in order to give voice to their experiences with various facets of the course, as well as offer their suggestions for improving the course.

Many students lacked familiarity and comfort with our collaborative co-instructional approach. We experienced feelings of vulnerability when sharing our personal narratives, experiences, and research with students, particularly after receiving comments that interpreted this strategy as interjecting "too much personal opinion” into lecture. We were troubled by this feedback and began to question just how much personal information to include. We had attempted to be selective (sharing only the most relevant and applicable examples from our lives and our research studies and setting boundaries around these disclosures), yet students had not come to see it that way. 
Many students demonstrated resistance to particular topics and themes (e.g., exploring the ways in which they were privileged and how these privileges may have influenced their beliefs and behaviours). Comments such as "I sometimes feel judged for being White" and "I often feel uncomfortable during lecture due to the way Caucasian people are portrayed" seemed prevalent among the interim feedback we received. We wondered whether we could have approached these topics in more sensitive ways, and whether we had risked alienating students.

One of our most significant struggles involved negotiating identities that others regarded as being synonymous with marginality and powerlessness within the institution (e.g., young age, female gender, minority identity, graduate student status). Some of the students singled out these identities in an obvious way, in order to highlight their perceptions of us as inexperienced and to discount our legitimacy as instructors. We also experienced challenges and frustrations when our "ideal” teaching philosophies did not always align with some of the approaches we utilized in order to negotiate the realities of this classroom context. For instance, we struggled with classroom management issues, large class size, and the inflexible arrangement of the lecture hall. We found it difficult to develop relationships and rapport with students.

Finally, we had not adequately prepared for the heavy administrative workload involved in managing a course of this size. An abundance of time was utilized in maintaining our course website, coordinating schedules and meetings with teaching assistants, responding to students' emails, arranging guest speakers, as well as developing rubrics and marking schemes to assess students' assignments. This time took away from what we perceived to be the more important focus: that of course design and delivery.

\section{Moving Forward: Key Recommendations}

Based on our experiences teaching this course (including honest reflections on our perceived successes and shortcomings), we offer 10 recommendations that may assist future instructors when preparing teacher candidates to be ready to embrace the many forms of diversity that exist within Canadian classrooms.

1. Universities need to offer students opportunities to engage with various forms of diversity in genuine ways. We advocate for the inclusion of service learning placements or 
volunteer internships within courses such as this one, where students can visit homeless shelters, learning disability centers, programs for new immigrants, or places of worship, in order to understand as well as build respect and empathy towards minority groups. These placements will help undergraduate students merge theories that they learn about in their classes with practical, context-dependent approaches that are used to meet diverse groups’ needs.

2. Instructors must be proactive in facilitating student engagement within large undergraduate course lectures. In the future, we would consider integrating personal response systems (e.g., i>clickers), breakout discussion groups, games, and student-led activities to enrich students' learning experiences and their level of participation in lecture. Modeling such approaches for our future teachers would also help to demonstrate our genuine interest in accommodating various learning styles and preferences.

3. Instructors should carefully consider and strategically plan the sequencing of course content, particularly when addressing topics related to diversity. Based on our experiences, we would advise against beginning with intensely personal topics such as identity, beliefs, and White privilege. We found that students quickly developed feelings of anxiety, guilt, and resistance. It became difficult to move past these emotions. Instead, we would suggest beginning with a rationale for the inclusion of social justice approaches in education and we would encourage instructors to work together with their students to develop a set of ground rules for the creation and maintenance of safe, respectful, open, and inviting spaces to engage in critical conversations during lecture.

4. It is necessary to familiarize teaching assistants with individual developmental frameworks and provide them with adequate training workshops as well as ongoing supports to: (a) ease the process of understanding students' emotional and cognitive challenges when encountering diversity issues, and to (b) create opportunities for coming together and brainstorming strategies that can be utilized in seminars to address sensitive content and emergent conflicts in respectful ways.

5. Early on, instructors should engage in detailed conversations with students about their teaching approach (particularly if it is novel or unfamiliar to them). Ensure that students understand the rationale behind a particular teaching philosophy, including instructors' motivations for approaching lectures in a different way, the benefits of this approach for 
teacher candidates' learning (and future teaching), as well as how this approach connects to the broader objectives of the course. We can appreciate instructors' initial hesitations towards using a co-instructional dialogical approach in lecture, as it is time-consuming, involves extensive planning with a colleague, is not rewarded monetarily, and remains unfamiliar to students. However, we encourage instructors, departments, faculties, and universities to find ways to value and support this type of teaching, as it has transformative possibilities for both instructors and students.

6. It is helpful to establish a learning community that brings past and present instructors together for shared conversations and open dialogue. Instructors can learn a great deal from others' previous experiences and can adapt these suggestions to suit their classroom context and improve their practices. We appreciated the opportunity to dialogue with instructors and mentors, and we were grateful for their willingness to share resources with us. Likewise, we would have benefited immensely from being part of a supportive learning community throughout the term. Teaching this type of course is incredibly difficult, both cognitively and emotionally. More resources and supports are needed for instructors working in this area.

7. Instructors should consider utilizing a course reading package that integrates multiple texts written by numerous educational stakeholders from diverse backgrounds. The advantages of selecting an assortment of readings includes a broader coverage of the issues that instructors deem to be important to their course, opportunities to expose students to a variety of writing styles and perspectives, and the freedom to include regional or board-specific educational policies and curricula, which will raise students' awareness regarding the multiple kinds of diversity that are prevalent within particular geographic areas, as well as the practical teaching strategies that certain school boards support.

8. Concurrent Education Programs should consider integrating diversity issues content across courses rather than requiring students to take one isolated course in this area. Future teachers need continuous exposure to diversity issues and frameworks in order to internalize their importance and value. A one-time, twelve-week course will never do justice to the complexity and varied forms of diversity in Canadian schools. 
9. Employee-graduate students (individuals who study and work at the same institution) need ongoing supports to assist them with simultaneously negotiating their academic and employment roles and navigating complex institutional hierarchies and power relationships (between themselves and their departments, teaching assistants, and students). At times, they may feel powerless and vulnerable, which can impact their ability to (a) form relationships with students, (b) have voice in course decision-making, and (c) do their job effectively.

10. Instructors of Diversity Issues courses must engage in ongoing reflection on issues of differences and instructors' identity politics, and how they shape course planning, decision-making, and instructor-student interactions. Keeping a journal to make sense of one's experiences, emotions, and reactions is a useful strategy for stimulating reflective thought and practice.

The factors that affect teacher candidates' beliefs towards diversity include not only “education” and travel, but also exposure to individuals from different cultural and experiential backgrounds, as well as personal experience with discrimination. In cognitive studies, various developmental theories assist educators to appreciate the behaviours of students and to improve their educational effectiveness. These perspectives may also enhance instructors' empathy and attitudes towards students. After analyzing our experiences from both social-cultural and cognitive perspectives, we better understand the origins of dominant groups' resistance, which both reduces the tension that we encountered in our daily personal and professional lives, and encourages us to continue integrating sociocognitive frameworks, and to work on developing a better rapport with our future students. This, in turn, moves us from feelings of frustration and blame, towards more constructive engagement. Drawing on our past experiences, literature, and new understandings resulting from our collaboration, we convey to others that two individuals from different racial, cultural, and religious backgrounds can forge a committed alliance based on mutual respect and a shared commitment towards social justice and equity. We hope to inspire others to take risks, collaborate, and allow themselves to be open-minded, considering the incorporation of multiple perspectives and approaches when preparing future teachers to embrace diversity. 


\section{References}

Brayboy, M. J., Castagno, A. E., \& Maughan, E. (2007). Equality and justice for all? Examining race in education scholarship. Review of Research in Education, 31, 159-194.

Brock University. (2009). EDUC 2P65 diversity issues in schooling. In Brock University 20092010 undergraduate calendar. St. Catharines, ON: Author. Retrieved from http://www.brocku.ca/webcal/2009/undergrad/EDGU.html\#EDUC_2P65

Bullock, K. (2002). Rethinking Muslim women and the veil. Herndon, VA: International Institute of Islamic Thought.

Darder, A., Baltodano, M., \& Torres, R. D. (2003). The critical pedagogy reader. New York: Routledge.

Doll, W. E., \& Gough, N. (Eds.). (2002). Curriculum visions. New York: Peter Lang.

Egbo, B. (2009). Teaching for diversity in Canadian schools. Toronto: Pearson.

Freire, P. (1970). Pedagogy of the oppressed. New York: Continuum.

Giroux, H. A. (1988). Teachers as intellectuals. Granby, MA: Bergin \& Garvey.

Giroux, H. A. (1997). Pedagogy and the politics of hope: Theory, culture, and schooling a critical reader. Boulder, CO: Westview Press.

Giroux, H. A. (2000). Insurgent multiculturalism and the promise of pedagogy. In E. Manuel Duarte \& S. Smith (Eds.), Foundational perspectives in multicultural education (pp. 193-212). New York: Longman.

Goodman, D. (2001). Promoting diversity for social justice: Educating people from privileged groups. Thousand Oaks, CA: Sage.

Gramsci, A. (1985). Selections from the prison notebooks (Q. Hoare \& G. Nowell, Eds. \& Trans.). New York: International.

Hamdan, A. (2006). Arab women's education and gender perceptions: An insider analysis. Journal of International Women's Studies, 8(1), 52-64. Retrieved from http://www. bridgew.edu/soas/jiws/Nov06/Hamdan.pdf

Hollins, E. R., \& Guzman, M. T. (2005). Research on preparing teachers for diverse populations. In M. Cochran-Smith \& K. M. Zeichner (Eds.), Studying teacher education: The report of the AERA panel on research and teacher education (pp. 477-548). Mahwah, NJ: Lawrence Erlbaum.

McIntosh, P. (1990). White privilege: Unpacking the invisible knapsack. Independent School, 49(2), 31-36.

McLaren, P. (2003). Life in schools: An introduction to critical pedagogy in the foundations of education. New York: Allyn and Bacon.

Mukherjee, A. P. (2001). In but not at home: Women of colour in the academy. Resources for Feminist Research, 29(1/2), 125-135.

Rodriguez, A. J. (1998). Strategies for counter resistance: Towards socio-transformative constructivism and learning to teach science for diversity and for understanding. Journal of Research in Science Teaching, 35, 589-622.

Rummens, J. A. (2003). Conceptualising identity and diversity: Overlaps, intersections, and processes. Canadian Ethnic Studies, 35(3), 10-25.

Sethi, M. (2001). Out in the cold: Surviving graduate school as a woman of colour. Resources for Feminist Research, 29(1/2), 136-141.

Shor, I. (1999). What is critical literacy? In I. Shor \& C. Pari (Eds.), Education is politics: Critical teaching across differences K-12 (pp. 1-30). Portsmouth, NH: Boynton/Cook. 
Singleton, G. E., \& Linton, C. (2006). Courageous conversations about race. Thousand Oaks, CA: Sage.

Turner, C. S. V. (2002). Women of color in academe: Living with multiple marginality. Journal of Higher Education, 73, 74-93. doi: 10.1353/jhe.2002.0013

van Dijk, T. A. (1993). Principles of critical discourse analysis. Discourse \& Society, 4, 249283. doi: $10.1177 / 0957926593004002006$

van Dijk, T. A. (2002). Discourse and racism. In D. Goldberg \& J. Solomos (Eds.), The Blackwell companion to racial and ethnic studies (pp. 145-159). Oxford: Blackwell.

van Dijk, T. (2006). Discourse and manipulation. Discourse and Society, 17, 359-383. doi: $10.1177 / 0957926506060250$

Wall, S. (2008). Of heads and hearts: Women in doctoral education at a Canadian university. Women's Studies International Forum, 31, 219-228. doi: 10.1016/j.wsif.2008.04.007

Zine, J. (2008). Lost in translation: Writing back from the margins. A roundtable response to Miriam Cooke’s “The Muslimwoman.” Journal of Feminist Studies in Religion, 24(1), 110-116. 